Int. J. Electrochem. Sci., 11 (2016) $6959-6975$

\title{
Aqueous Extract of Salvadora Persica as a Novel Green Corrosion Inhibitor for Low-Alloy Steel in Acidic Media - Part I
}

\author{
Aliaa A. M. Hassan ${ }^{1}$, Hesham T.M. Abdel-Fatah ${ }^{2, *}$ \\ ${ }^{1}$ Faculty of Science and Arts in Al-Ardha, Jazan University, Al-Ardha, Jazan, Saudi Arabia. \\ ${ }^{2}$ Department of Corrosion Research, Central Chemical Laboratories, EEHC, Cairo, EGYPT \\ "E-mail: hesham_tm@yahoo.com
}

doi: $10.20964 / 2016.08 .48$

Received: 13 April 2016 / Accepted: 7 June 2016 / Published: 7 July 2016

\begin{abstract}
The corrosion inhibition characteristics of aqueous extract of Salvadora Persica (AESP) on low chromium-molybdenum steel (ASTM A213) grade T2 $(0.5 \mathrm{Cr}-0.5 \mathrm{Mo})$ in $1 \mathrm{M}$ hydrochloric acid solutions has been studied chemically and electrochemically at different temperatures. The protection efficiency in absence and presence of AESP was investigated by using mass loss method, Inductively Coupled Plasma Optical Emission Spectrophotometer (ICP-OES), as will as potentiodynamic polarization, electrochemical impedance spectroscopy (EIS), and electrochemical frequency modulation (EFM) techniques. The protection efficiency was found to increase with a corresponding increase in the AESP concentration and decrease with temperature. Amongst the different adsorption isotherms, the studied compound more closely followed the Temkin isotherm. The values of standard free energy of adsorption ( $\Delta G^{o}$ ads $)$ revealed that AESP is adsorbed on the low-alloy steel surface via physisorption mechanism.
\end{abstract}

Keywords: acid cleaning, hydrochloric acid, low-alloy steel, corrosion inhibition, Salvadora persica, mass loss, EIS, EFM, ICP-OES.

\section{FULLTEXT}

(C) 2016 The Authors. Published by ESG (www.electrochemsci.org). This article is an open access article distributed under the terms and conditions of the Creative Commons Attribution license (http://creativecommons.org/licenses/by/4.0/). 